\title{
Responsibilities for Climate Damage within Borders: Reconciling Liability with Shared Responsibility
}

\author{
Kumie Hattori
}

Citation: Hattori, K. Responsibilities for Climate Damage within Borders:

Reconciling Liability with Shared

Responsibility. Philosophies 2021, 6, 65 . https://doi.org/10.3390/

philosophies6030065

Academic Editors: Erik Persson,

Åsa Knaggård, Kerstin Eriksson and Marcin J. Schroeder

Received: 10 May 2021

Accepted: 12 July 2021

Published: 3 August 2021

Publisher's Note: MDPI stays neutral with regard to jurisdictional claims in published maps and institutional affiliations.

Copyright: (c) 2021 by the author Licensee MDPI, Basel, Switzerland This article is an open access article distributed under the terms and conditions of the Creative Commons Attribution (CC BY) license (https:// creativecommons.org/licenses/by/ $4.0 /)$.
Graduate School of Global Environmental Studies, Kyoto University, Kyoto 606-8501, Japan; hattori.kumie.54a@st.kyoto-u.ac.jp

\begin{abstract}
The literature on climate justice has primarily focused on distributing the benefits and burdens of climate change, particularly those related to the costs of mitigation and adaptation. As such, less attention has been paid to emerging political issues surrounding loss and damage caused by the failure of mitigation and adaptation. This paper aims to fill this gap through discussions on reparative justice, which is correlated with the concept of liability. Since the concept of liability has controversial implications in climate politics and theory, investigating reparative justice for climate damage must clarify how the concept of liability can reconcile with the normative theory of political responsibility. This paper begins with the question of how the distributive justice scheme fails to discuss climate damage, by arguing that the scheme does not necessarily recognise a prior injustice and misses the need for reparation for the extensive scope of climate loss and damage. Then, it shows that the concept of reparation, which differs from compensation, holds more promise in giving the proper due for climate loss and damage. Finally, after comparing the liability model and the shared responsibility model proposed by Iris Young, this paper concludes by proposing that the hybrid model of liability and shared responsibility can be used to avoid limitations of the concept of liability.
\end{abstract}

Keywords: climate justice; loss and damage; reparative justice; compensation; disaster victim assistance; structural injustice

\section{Introduction}

Political philosophers have primarily developed the concept of distributive justice in the climate change context, which I refer to as 'distributive climate justice'. They focus on the allocation of responsibility for the benefit and burden in regard to two main types of climate policy: mitigation and adaptation. Mitigation policy aims to reduce net greenhouse gas (GHG) emissions, while adaptation policy copes with the negative consequences of global warming. Discussions on these policies have been taking place since the early stages of climate change, when threats related to the phenomenon were still largely theoretical. However, current trends point towards how inefficient mitigation and adaptation would result in harmful effects, and these two key types of climate policy seem to be 'incomplete' [1].

As the negative impacts of climate change become more apparent, questions about its anthropogenic causation intensify. It is then that the third category of compensation, or reparation as I will argue later, comes into the sphere of climate justice. Since the 2000s, scientists have attempted to show through the study of extreme weather event attribution (hereinafter 'attribution science') that it is possible to link unusual weather events with human GHG emissions ${ }^{1}$. The more substantial the evidence from these studies, the more the questions about loss and damage become inevitable. Despite these emerging issues, there has been little attention paid to compensatory or reparative justice for damage caused by climate change ${ }^{2}$. Therefore, the primary purpose of this paper is to fill this gap in the literature of climate justice by investigating justice for climate damage. While the difference between loss and damage will be further elaborated on in Section 2, I will collectively refer to these two concepts as 'climate damage' in this paper. 
The second purpose of this paper concerns the deviation from the global dimension of climate justice. Once compensation becomes the issue, it is within the range of corrective justice to require a liable party to pay for the damage after the correlation between the victim's damage and the culprit's act is identified. However, bringing up the notion of liability has been controversial in both politics and theory related to climate change. In politics, despite the demand for compensation from highly-at risk countries of the developed countries, including the members of the Alliance of Small Island States (AOSIS), the Warsaw International Mechanism (2013) does not have provisions for liability or compensation, but only 'dialogue' [14] (Decision 2/CP.19, para. 5). Although Article 8 of the Paris Agreement (2015) addresses 'loss and damage', COP21 explicitly denies any basis for liability or compensation [15] (Decision 1/CP.21, para. 51). This points towards one of the reasons why theorists regard the liability argument as flawed: anxiety over the discourse on liability or culpability may create a divisive adversarial appearance that contrasts with the need for cooperation in international politics [16] (pp. 330-332) [17] (p. 678). Even authors who write about loss and damage simply doubt the political feasibility of the liability argument. Referring to the decision accompanying the Paris Agreement which denies 'any liability or compensation', they regard the liability argument as a 'political deadlock' [6] (p. 54).

Yet, some of these hurdles disrupting the discussion of liability are related to the global dimension of climate justice. In contrast, when discussing the topic within borders, some of these hurdles can be avoided. The rapidly increasing number of climate litigations raises the issue of liability, where both government and private actors, such as oil companies (the so-called Carbon Majors), are sued for damages ${ }^{3}$. Then, since the modern theory of tort embodies corrective justice as its core idea, a possible compensatory scheme can be readily grasped by assuming a domestic legal system that operates more effectively than the international legal order does. Furthermore, placing liability at the domestic level and focusing on individuals instead of a country allows us to recognise the needs of climate victims more effectively, since the rigorous verification of facts related to damage is what the domestic courts aim for and the treatment of disaster victims is primarily a task for the national or local government, not the international community. Thus, the diverse claims on justice for damage and the public responses can be closely seen within borders, whereas the scholarship of climate justice primarily presupposes allocation issues between countries. Viewing this gap, the second purpose of this paper is to examine the argument of liability for climate damage through a subnational perspective. The way to move from global discussions to a subnational perspective is by generalising the former: the paper will first examine global discussions in the literature, and thereupon generalise it to the subnational while also adding further considerations.

When the subnational perspective highlights the need and practice of compensation for climate victims, the controversy of the notion of liability becomes notable. Though attribution science can support the causation of harm to a limited extent, it is still difficult to identify the harm correlated to relevant parties, and this has been used as a core argument against climate change compensation [21] (pp. 110-118) [22] (pp. 116-227). As such, there remains room for unproven damage where people cannot uphold corrective justice. This exacerbates the controversy over the liability claim, resulting in frustrated blame and defensive backlash. Since conventional morality and law paradigmatically limit the scope of responsibility to identifiable deliberate individual action, we need a new conception of responsibility to climate damage whose specific cause and wrongdoer may not be entirely specified-and reforming the conception can entail reconstructing the moral, political, and legal aspects of responsibility, since the concept permeates our institutions and practices [23] (p. 84). Then, an attempt for a shift from a conventional view of responsibility must start from the actual constraints, not from ideal conditions, as required by Steven Gardiner's 'ethics of the transition' [12] (p. 400). Hence, given that the growing call for compensation and its controversial political implication manifests the irreconcilable aspects of the conception of responsibility to climate damage, this investigation must address the 
following question: How can the controversial aspects of liability adjust or reconcile with political responsibility to climate damage? This research question has implications for both international and subnational considerations. It should be admitted, though, that climate damage and the practice of compensation are highly context-dependent; the severeness and nature of climate damage vary according to the area, and the majority of lawsuits for climate compensation are filed in the United States. Nevertheless, as climate damages occur worldwide, and the human need upon loss as well as the justification for rectification can be common regardless of any nation-state, this theoretical investigation can generally apply. Though the discussion on an institution in Section 4 pertains to democratic societies, it is still relevant to societies with other political systems.

The discussion of this paper will proceed as follows. Section 2 begins with the examination of how the distributive justice scheme fails to address climate damage, as the scheme does not start from the recognition of injustice and misses the need for reparations for the extensive scope of climate damage. Section 3 will distinguish the concept of reparations from compensation, and argue that reparation holds more promise in giving the proper due for climate loss and damage. The end of the section shows how the discussions of dominant literature apply to the domestic level. Section 4 then compares the liability model and the shared responsibility model proposed by Iris Young. To conclude, this paper proposes that the hybrid model of liability and shared responsibility can be used to avoid the limitations of the concept of liability.

\section{Distributive View Examined}

Compared to other types of justice, the distributive principle is prevalent in the field of climate justice. While the contemporary distributive approach varies depending on its scope (whom to distribute), shape (how much to distribute), and currency (what to distribute) [24] (pp. 50-51), discussions of climate distributive justice are commonly defined within the global and intergenerational dimensions ${ }^{4}$. Given the global dimension of the phenomenon and policy actions related to climate change, a bulk of the literature on climate distributive justice is concerned about the international allocations of mitigation and adaptation costs, in addition to emissions among countries [1,26] (ch. 2-3) [27] (p. 314) [25] (p. 123). Among theorists, Henry Shue provides the following four primary questions regarding climate policy: (1) What is a fair allocation of the costs of preventing global warming? (2) What is a fair allocation of the costs of coping with the social consequences of the inevitable global warming? (3) What background allocation of wealth would allow international bargaining to be a fair process? (4) What is a fair allocation of emissions of greenhouse gases [28] (ch. 2)? Similarly, Stephan Gardiner raises three basic questions of climate policy: (1) where to set a global ceiling on emission, (2) how to distribute the emissions, and (3) what to do about unavoided impact. Among Gardiner's questions, the second on the distribution received the most theoretical attention from the justice perspective [27] (p. 314). These are more or less common questions among theorists and the language of distribution affects the formulation of all questions (see, for example, ref. [29,30] (pp. 66-76) [31,32] (pp. 26-39) [33-35] (pp. 131-132)).

The distributive principle has a limitation on the way that we consider negative impact. For example, when Shue formulates the second question of coping costs, i.e., adaptation costs, he uses the term 'correction' for the harmful effects of climate change, for which he only illustrates with an example of constructing sea walls [16] (pp. 54-55). Given that he equates coping costs to corrective costs (at least partially), this distributive scheme for correction of climate damage largely misses the currently occurring and predictable losses and damages caused by climate damage. If this limitation of the distributive scheme was simply a matter of factual assumption, the limitation could be remedied by recognising loss and damage. For example, Dale Jamieson's categorisation includes a wider range of the damage. He regards constructing a sea wall as 'anticipatory' adaptation based on foresight, and also provides an additional category of 'reactive' adaptation that is based on immediate events. An example of reactive adaptation is a coastal community that has 
been rebuilt to a more secure standard after being damaged by a hurricane [36] (p. 265). In this line of thought, distributing reactive adaptation costs may cover damages that are of concern at this stage.

On the other hand, there is still a limitation of the distributive mindset itself. While reactive adaptation presupposes actual damage and harm, distributive justice does not necessarily consider the distinctive meaning of damage in the first place. The distributive centred principle can lead one to think in a way that 'rectification or compensation will be needed to produce a just distribution' [32] (p. 26) (italics added). In contrast, corrective justice demands rectification or compensation of damage per se, that does not directly translate into an allocation issue. Without the assumption of a prior injustice, the trade-off between harms and benefits can easily be introduced: while theorists argue against the cost and benefit analysis in terms of adaptation, and argue for the moral superiority of mitigation to adaptation (for example, ref. $[36,37]$ (p. 68)), the distributive scheme may allow skipping the normative consideration of damage that corrective justice categorically evaluates as injustice.

Even recent literature which discusses compensation as the distinctive third category of climate policy faces a limitation when the language of allocation is used. Steve Vanderheiden considers the preceding stage at which mitigation is not enough and adaptation fails. He admits that distributive justice is not remedial when considering past inequity, and therefore, corrective justice imperatives are not satisfied by merely extending the scope of distributive justice [37] (pp. 74-75). However, he thinks that since the adaptation cost is derived from not only historical emissions but also from recent mitigation efforts, adaptation costs should not be allocated to developing countries without being linked to mitigation costs. Thus, he claims that the basis linking the two must be under 'a single overarching conception of justice' which transcends the distributive and corrective conceptions [37] (p. 71). However, his argument is limited in that he is less concerned about the nature of damage than about fair treatment for those who are not responsible for emissions. Since his concept of justice requires neutralising the 'bad luck' of vulnerable countries, this overarching view presupposes that adaptation cost and compensation can be commensurate in a common demeanour of the burden attributed to liable countries. Consequently, this view regards other forms of responsibility such as 'apologies, agent regret ... liability to punishment, or the fitness of moral praise and blame' as merely 'ancillary questions' [37] (p. 76). As such, while this view has significant implications for allocating costs between countries, a criticism of distributive justice theory can apply here as well: the principle of distributive justice focuses on easily identifiable distributions by restricting the meaning of social justice to the proper distribution of benefits and burdens, and excludes what cannot be measured ${ }^{5}$ [39] (pp. 15-16). Theorists who engage in pursuing fair allocation are thus led to underestimate the unmeasurable nature of damage, and may inadequately materialise the form of compensation as well.

It is noted that this discussion does not necessarily exclude the possibility of material compensation for climate damage. Distributive justice as an independent principle can play an important role to deal with undeserved harms to climate victims, when natural climate variation is considered, and a liable party cannot offer full remedy [16] (p. 44). On the other hand, distributive justice does not provide further differentiated analysis of the nature of climate damage. The differentiated analysis should consider the perspective of climate victims who suffered from injustice-otherwise the justice principle may omit the need for other forms of correction outside the scheme of allocations.

\section{Reparative View}

Contrary to those who focus on the distributive principle, some philosophers provide insights into the nature of damage by focusing on the climate vulnerable, such as 'climate refugees $^{\prime}{ }^{6}$. This section shows the distinctive needs of the climate vulnerable from the reparative point of view, while discussing at the domestic, or subnational, level. For this discussion on rectification, I will introduce two binary categories consisting of two 
elements: (1) reparation (offered only by the liable party) or compensation (offered by either the liable party or the third party), and (2) monetary or non-monetary rectification.

Corrective justice requires that the injustice be rectified by the wrongdoer through the payment of damages to the victim. It is a central idea of tort law since the contemporary debate contested with the utilitarian approach [43]: by removing the unlawful gain from one and returning it to make up for the loss of the other, the correction results in a restoration of the original equality of the two [44] (p. 349). George Fletcher calls the 'paradigm of reciprocity' as one of the basis of torts, under which 'a victim has a right to recover for injuries caused by a risk greater in degree and different in order from those created by the victim and imposed on the defendant' [45]. By extension, corrective justice in the climate change context can simply take the form of requiring compensation by emitters who are responsible towards those damaged by the result of emission. This imperative assumes the damage as a violation of one's right, and therefore implies that whether a certain damage constitutes injustice or not depends on the basis of the right. Although the understandings of the basis to claim damage are contested, such as in the cases of human rights [46], capabilities [35], human securities [47], or human development [48], the aim of corrective justice is clear. The compensatory aspect of corrective justice is effectively viewed as a victim- and person-centred method of neutralising injustice compared to other types of justice, such as retributive justice [49] (p. 480).

Another essential element of corrective justice concerns the identification of the parties correlating with the injustice. As corrective justice requires the rectification to be performed by the liable party, it is vital to distinguish between compensation offered by a liable party and one by a third party. In this case, classifying forms of rectification into 'compensation' and 'reparation' will be beneficial. According to Bernard R. Boxill, compensation cannot replace reparation as they have different aims [50] (p. 115-119). While reparation is due only after injustice, compensation may be due even when no one has acted unjustly to another. For reparation to be complete, the injurer must also acknowledge the wrongfulness of his act so that he can reaffirm the other's equality as well as the injured can reject the allegation of his inferiority contained in the injurer's behaviour [50] (pp. 118-119). Moreover, in this binary understanding of reparation and compensation, the form of rectification can also make a difference. Compensation is generally understood as the payment of money or goods to recognise specific harms, while the forms of reparation may not be money or goods. Hence, although the definition and conditions may vary, I understand that compensation and reparation are two different approaches in terms of their form and the agent who offers the rectification. As such, both approaches can be supposed by considerations of corrective justice in the two ways: reparation embodies the idea of restoration by a wrongdoer; the form of paying for damage is common to compensation.

In a similar vein, some theorists contrast compensation with reparation(s) in an attempt to highlight that only those responsible for the harm caused can rectify the injustice [51] (pp. 40-42) [52]. For example, Rebecca Buxton points out that conceptualising justice for climate refugees as a matter of compensation misses a key feature of the rise in sea levels due to global warming, that is, 'the plight of climate refugees is caused by the emissions of other states' [7] (p. 199). This again highlights that the imperative of corrective justice requires restoring the original equality of the two. From the perspective of corrective justice which requires the restoration by a wrongdoer, the discussion of climate damage should prioritise the reparative approach rather than the compensatory approach.

\subsection{Limitations of Corrective Justice}

The process of introducing corrective justice to the context of climate change has encountered several objections. There have been persistent doubts concerning the identifications of wrongful acts and the relevant parties. Critics argue that since we do not know which specific damages and victims are related to which wrongdoers, the scheme of corrective justice cannot apply [21] (p. 216-218) [22] (pp. 100-118) [8] (p. 736-739). However, the basis of their concern depends on a factual situation, which is currently 
changing-attribution science now provides substantial evidence of the causation of a specific disaster and climate change. That is, specific contributions of a single emitter are being identified, and face more allegations than ever before ${ }^{7}$.

On the other hand, there are still unavoidable limitations to climate corrective justice in respect to evaluating injustice and the forms of rectification. The distinction of 'damage' and 'loss' will clarify this point. Based on the distinction of the UNFCCC stipulation, 'climate damages' refers to negative impacts which can be restored. Examples of this include windstorm damage to the roof of a building, or damages to a coastal mangrove forest as a result of coastal surges. On the other hand, 'climate loss' refers to negative impacts which are impossible to restore, such as the loss of freshwater resources [53] (p. 3). In particular, scholars discuss the nature of climate loss in the issues of climate refugees. Avner de Shalit claims that environmental displacement caused by climate change constitutes 'a strong and special case of environmental injustice' [54] (p. 310). Unlike less serious cases where people have to move due to a temporary flood, refugees who are evacuated from their sinking land due to the rise of sea levels will forever lose their land. This involves not only a loss of their home, but also a loss of a sense of place, therefore the loss of the functioning of one's identity [54] (pp. 316-323). The observation of the loss of identity formed by the environment has much in common with the loss of identity formed by a group one belongs to, as both are based on an empirical phycological status [55]. Clare Hayward also considers the cases of those who lost their lifeline or their home itself. These cases include the Inuit people, whose lives around the Arctic Circle have been significantly impacted, or the nations of people living on low-lying atoll islands which are at risk of total submersion due to the rise of sea levels. Through such cases, Hayward develops the concept of 'cultural injustice', which is defined as 'threatening cultural identities' [9]. Cultural injustice is categorised into 'territorial dispossession' and the 'loss of a traditional way of life' due to the impact of climate change. She claims that the substitution of items such as food and water sources is not sufficient to cover all significant human interests and to remedy cultural injustice [9] (p. 163). As such, the loss of one's environment, culture, or community demands the recognition that clearly shows their deprivation is unjust ${ }^{8}$.

The unjust nature of climate loss indicates that the compensatory aspect of corrective justice can be inadequate. There is an argument for the impossibility of compensation: It claims that we can never know whether compensation was adequate to cover losses, because the losses and compensation are incommensurable [49] (p. 57). This scepticism leads us to investigate how and why compensation can be legitimised. Robert Goodin introduces the distinction between means replacing compensation and ends-displacing compensation. The former means 'to provide people with equivalent means for pursuing the same ends' (compensation ${ }_{1}$ ), while the latter means 'to compensate people, not by helping them pursue the same ends in some other ways, but rather by helping them to pursue some other ends in a way that leaves them subjectively as well off overall as they would have been had they not suffered the loss at all' (compensation 2 ) [49] (p. 60). Goodin claims that

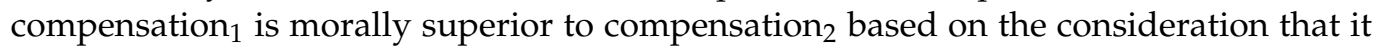
respects people's autonomy to choose their own life plan. In the case where irreplaceable objects have been lost, compensation ${ }_{2}$ might be the only possible compensation and is 'better than nothing', though it is still 'inadequate' [49] (pp. 66-69, 73-74). Hence, regarding the question of the possibility of compensating for climate loss, the answer, according to Goodin, would be that 'it is possible, but necessarily inadequate'. Thus, due to the theoretical difficulties of evaluating injustice and the monetary form of compensation, the rectification of loss must deviate from the classical view of corrective justice.

\subsection{Reparative Approach}

In contrast to the compensatory aspect of corrective justice, rectification measures must take flexible forms in considering the nature of the permanent loss of land and culture. Toward a conception of a more flexible form of reparations, Alfred L. Brophy [56] understands reparations as the incorporation of the backward and forward-looking program. 
On the one hand, it is a program that one justifies by past harm, and is designed to assess and correct the harm. On the other hand, it recognises that past harm has a current and continuing effect, and aims to improve the lives of victims in the future [52] (pp. 522-523). The former consideration is based on corrective justice, while the latter consideration is a political project beyond corrective justice. As such, it allows for flexibility in choosing the type and size of the remedy [52] (p. 523) [57] (pp. 459, 461). Maxine Burkett applies the reparative program to the climate change vulnerable. She proposes that the reparations effort must contain three elements; an apology, monetary or other measures that give actual or symbolic weight to that apology, and the guarantee of non-repetition [52] (pp. 526-534). Burkett's proposal has overlapping considerations with other scholars who focus on climate injustice. Heyward suggests four measures for cultural injustices: a remembrance of the story of climate change victims, fostering continuous narrative, ensuring group control over the process of change, and acknowledgement of injustice [9] (pp. 163-165), and Buxton proposes that preparing new land for climate refugees is more commensurable with their loss. Taking into account that there are practical problems of ceding another country's territory, Buxton concludes that the provision of a new floating island solves the problem of ceding territory, and also recognises the value of the community [7] (p. 217). In these ways, since the discussion of justice for climate refugees assume that the value of the homeland is tied to people's cultural identities, theorists observe that climate victims are not compensated merely in a monetary aspect, or through the provision of land in other country's territory.

Yet, it is noted that the current discussion does not necessarily exclude the considerations for monetary compensation or protection offered by a third party. As climate injustice can distort human life in various ways, the involvement of third parties might have emerged from international assistance or compensation on the grounds of mutual aid, humanitarian consideration, or global justice. The discussion only indicates one of the cases where a flexible form of reparation is preferable to monetary compensation.

The discussions on the climate vulnerable thus far presuppose that the issues take place on a global level. However, the insights gleaned are in turn applicable to the domestic. Environmental displacement and the loss of homeland occur at the subnational level considering the high possibility of localised disasters caused by climate change. Hurricanes, heavy rainfall, and any other impacts due to climate change can deprive or distort part of, or the entire area, of people's land, resulting in the loss of their lifestyles and livelihood. Given the nature of the losses that are and will occur worldwide regardless of countries, the argument of reparation for climate injustice can provide an analytical frame for the discussion within borders. In terms of the identification of victims, it is often more evident when we focus on the actual disaster at the subnational level. Regarding the liable agent discussion, many climate change litigations hold domestic private companies and governments responsible for compensation for climate damage. While there are important cases where climate change victims raise their voices to the international organisations, the primary agents who can conceive the damage and respond to victims can be entities in the same jurisdiction. Hence, the discussion on responsible actors must extend to governments, municipalities, companies, nongovernmental organizations, and individuals at the national level.

\subsection{Objections}

The reparative approach encounters criticism because it has a politically unwelcome implication. This criticism typically appears in the discussion about 'climate debts'. The metaphorical term, climate debts, is one way of providing a framework for understanding how the responsibilities for past emissions should be distributed. Jonathan Pickering and Christian Barry interpret common arguments for climate debt as having the following features: (1) moral responsibilities, (2) a debt that is claimable as a matter of right, (3) the content of the responsibility, (4) identity of debtors and creditors (specifically by developed countries towards developing countries), and (5) form of repayment required, which is 
similar to the repayment of emission debt and adaptation debt [17] (p. 670). While Pickering and Barry defend the coherence of the concept of climate debt, they do not acknowledge the political value of the concept due to its adversarial emphasis on dividing the world into debtors and creditors [17] (p. 679). They admit that the rhetoric of climate debt may at best serve to challenge the intransigence of countries that have failed to take sufficiently strong action to curb climate change. On the other hand, an international multilateral framework that is freely accepted by the 194 parties to the UNFCCC aims to address climate change effectively. In such a cooperative situation, the idea of climate debt may be perceived as 'a mere slogan, in the process tarring the idea of climate justice ... with the same brush' [17] (p. 679). Furthermore, since many developed countries link the idea of debt with that of reparations, Pickering and Barry think that it raises uncomfortable and politically contentious issues, such as reparations for slavery and colonial injustices. Therefore, they conclude that it is improbable that the concept of climate debts provide the foundation for a specific policy framework that allocates responsibilities among countries [17] (p. 680).

Even though their view supports real politics, it is nonetheless hasty to abandon the divisive relationship of the claimant and the responsible. Identifying victims and wrongdoers is an essential component of the reparative view. As the argument for climate injustice shows, correcting climate damage requires not only the distribution of the burden and benefit, but also distinctive measures based on the recognition of the special case of damage. As such, the reparative view entails the recognition of injustice by a liable party, as well as an investigation of an appropriate form of reparations beyond monetary compensation. If we admit the case for the need and significance of reparation, the next question is how the reparative view or the liability view can reconcile with criticism based on a political value of responsibility.

\section{Political Responsibility for Creating a Reparative Scheme}

This section examines the compatibility between liability and political responsibility. Before the examination, the concept of responsibility should be clarified. H.L.A. Hart divides responsibility into four types; liability-responsibility, casual-responsibility, capacityresponsibility, and role-responsibility [58] (p. 211). He takes liability-responsibility as the primary sense of responsibility through analysing its etymology [58] (p. 265). It is parallel with the concept of liability that we have examined throughout this paper as both refer to a legalistic category. Since capability-responsibility and casual-responsibility are derived from the primary sense of liability-responsibility as the criterion of liability, only role-responsibility is less connected to the notion of liability [58] (p. 211). Given the essential difference between liability-responsibility and role-responsibility, the distinction of liability-responsibility and role-responsibility can be understood to belong to different categories, legal and non-legal.

Iris Young offers criticism against the liability model from the viewpoint of rectifying social injustice. Young explicitly contrasts what she calls the liability model of responsibility with the 'shared responsibility' model [59]. According to her, the liability model of responsibility contains liberal moral and legal accounts of responsibility that combine causal responsibility, culpability, and the associated obligation to provide redress [59] (p. 95). This is roughly equivalent to Hart's category of liability-responsibility. Young basically rejects the liability model that focuses on blaming particular culprits because this backwards-looking model cannot rectify 'structural injustice' - a specific kind of moral wrong distinct from the wrongful action of an individual agent or the repressive policies of a state. Structural injustice is generated by a consequence of the collective activities by individuals in their pursuit of particular goals and interests [59] (pp. 44,52). Unlike the liability model that detects identifiable wrongdoers, structural injustice involves 'all those who contribute by their actions to structural processes with some unjust outcomes engaged in cooperation' [59] (p. 96).

The reasons why the liability model is not politically productive to rectify structural injustice can be summarised as follows [59] (pp. 116-118). When placed in political contexts 
where the harms or wrongs involve large-scale and long-term social structural processes, the rhetoric of blame leads to 'defensiveness in response', by which we are distracted from cooperating for change in two ways. First, the model tends to become backwards-looking rather than attempting to change the situation (back-looking view). Second, it also divides people into powerful wrongdoers, often public officials, and innocent ordinary people, leading to blame the former by simplifying the cause of the injustice (blame-switching). Young observes that blame-switching in structural injustice is particularly easy because people do in fact participate through their actions in the processes that produce unjust outcomes. As such, blaming a few powerful actors allows many ordinary actors who are participating in the process to deny their contribution and responsibility. Furthermore, even though people do admit their guilt, the liability model can be still unproductive to change the overall structure because people will become more focused on their own actions or character, which distracts from the objective discussion of how social structures operate, and what can be done to change them (less focus on structures).

Contrarily, Young proposes the concept of shared responsibility based on her 'social connection model'. She understands that being responsible for structural injustice means that 'one has an obligation to join with others who share that responsibility in order to transform the structural processes to make their outcomes less unjust' [59] (p. 96). Since people participate in the social structures that systematically produce harm, they have to be accountable for reducing such harm. Specifically, in terms of state policy, political responsibility for structural injustice involves making 'vocal criticism, organised contestation, a measure of indignation, and concerted public pressure' [59] (p. 151). While the contents of responsibility remain abstract, she also identifies four groups of people responsible for justice: those who have power, privilege, interest, and collective ability [59] (p. 144). Further, it is noted that by understanding shared responsibility as political, Young does not regard it as official duties of any specific polity such as democracy or aristocracy. Political responsibility, according to her, derives from 'belonging together with others in a system of interdependent processes of cooperation and competition through which we seek benefits and aim to realise projects' [59] (p. 105). In this way, Young's conception of political responsibility is broad enough to assign the responsibility for justice as a citizen to all who dwell within the structures regardless of a polity.

\subsection{Application to Climate Change}

Continuing with this line of thought, can the argument of structural injustice apply to climate change both internationally and domestically? (For the application at the international level, see [60].) The answer is positive. As far as we interpret the harmful effects of climate change as structural injustice, all who participate in the emitting process have shared political responsibility to change climate structural injustice. Typically, developed countries, private companies, and all who participate in the institutional process emitting GHG unconsciously form the collective activity that contributes to climate change. This exact process produces the harmful effects of climate change and affects vulnerable countries and people.

It is important to note that while Young defends her idea of shared responsibility in contrast with liability, she does not deny the need for practices of blame and fault found in many legal and social situations. She admits that such practices are appropriate in some political contexts. For example, a public official who has made a disastrous decision without proper information and deliberation should be blamed [59] (p. 115). This implies that shared responsibility and liability can coexist simply because both are functional. It also indicates that her criticisms are neither against the concept of liability nor reparative justice, but against the effects of the notion. This leads to the question of when and how should we combine the shared responsibility model and the liability model.

Anthony Langlois points out the inefficiency of shared responsibility alone. According to him, the premier example Young uses to illustrate her theory about political responsibility for justice is the anti-sweatshop movement, which is unsuccessful in illustrating the efficacy 
of her political responsibility model [61] (pp. 56-59). Considering this failure, Robyn Eckersley admits the liability model has an important role to play in situations where (1) structural injustice persists, (2) the connections between culpability and harm are clear, and (3) there is no motivation for the powerful to transform social practice [62]. (p. 358). For this paper, these possible situations should be examined at a domestic level.

The first situation takes place when collective activities producing GHG are conducted by both individuals and groups, leading to areas and people damaged by climate change. Should the people suffering the damage be without resources and remedy to call compensation, we can reasonably say structural injustice persists in this situation. Second, the proof of the connection between culpability and harm of climate change is indeed the most problematic issue when establishing legal liability or duty. However, as discussed, the connection becomes common knowledge through the publication of scientific evidence, while citizens and non-governmental organisations make efforts to impose legal responsibility on particularly large emitters. In terms of the third situation, countries and the governmental responses are rapidly changing. With regard to mitigation policy, politicians and government administrations are currently moving towards the reduction of carbon dioxide emission more intensively than ever before. Nevertheless, it is still hard to say that those who have power have already moved towards the rectification of existing and prospective climate victims. Such neglect is a sign of the ingrained indifference of powerful parties towards loss and damage caused by climate change.

From the domestic viewpoint, there is an additional reason why liability has an especially important role: the public or governmental treatment for individual victims. Typically, climate change produces disasters that can be assisted for reconstruction by government policy and administrative schemes. The consideration of corrective justice makes a difference to such victim assistance. The assistance or compensatory scheme involves the investment of a high national treasury and consumption of public goods, which is under scrutiny by fellow citizens (such civil pressure is undoubtedly higher in, but not limited to, democratic societies). Compensation or condolence money for undeserved harm is undoubtedly crucial for disaster victims, when wrongdoers and their contributions are not specified and the loss is not sufficiently covered by them. In this situation, taking the perspective of distributive justice allows discussion on the basis of the distribution of assistance costs, which may lead to an unfavourable social reaction to victims, especially when the burden of assistance is heavy on other citizens ${ }^{9}$. It will more or less hinder the victims' resilience. In contrast, corrective justice is offered for injustice to be rectified without questioning whether the victims deserves or not. As stated above, the reparative approach of corrective justice is preferable to the compensatory approach in some cases of climate loss, and it is completed by the wrongdoer's reaffirmation of the victim's equality and the victim's rejection of his inferiority. Since it is contradictory to say corrective justice is performed without the recovery of victims' damage, liability should be pursued to accommodate a condition based on which climate victims reconstruct their lives. Then, even where compensation by a third party is at issue, the reparative view in turn encourages a third party's affirmation of victim's recovery from injustice. In this line of thought, corrective justice can supplementally support the governmental scheme of disaster victim assistance if reparation is not yet attainable. Thus, the attribution of liability is necessary not only because liability provides a criterion of remedy but also because it can be a part of the remedy itself. Accordingly, the liability model and the shared responsibility model should coexist, considering that both reparations and disaster victim assistance under the consideration of corrective justice are likely indispensable parts of their recovery.

\subsection{Divisional Political-Role-Responsibilities}

The question of how to reconcile the liability model and shared responsibility model now comes to the fore. As stated, Young does not thoroughly deny the room in which the notion of liability works against structural injustice. To Young, the fault of the liability model is the side effects of the legalistic concept on people's political attitudes and frames 
of thought; that is, a back-looking view, blame-switching, and distraction from structures. These liability side effects may disrupt people from sharing responsibility for cooperating to change the structure in which they participate. Thus, the core of the problem concerning liability lies in the application of the legalistic category to what we should basically discuss as a political responsibility. In other words, the side effects occur due to readily mixing or even replacing political responsibility with a legalistic concept of responsibility. Such a tendency to reduce the political issue to a legal framework is critically analysed as an ideology called 'legalism'. Legalism, according to Judith Shklar, is the ethical attitude that holds moral conduct to be a matter of legal rights and duties [62] (p. 1). It endorses the rigidity of legalistic categories of thought, and produces a result 'so deleterious' especially when the relationship of law to the political environment within which its functions is appraised [2] (p. 8). This explanation applies to the side effects of the liability model as a legalistic category. While Shklar concedes that there is no specific remedy for legalism, she reminds us that our political thinking has been permeated with legalistic notions and terms, making them inseparable [62] (p. 223). If so, the strategy to overcome legalism, specifically liability side effects, is not to decline the legalistic category altogether. Instead, a more negative strategy should be taken to limit the scope of the category, with the full recognition that the notion of liability can adversarially affect the rectification of structural injustice.

In order to consciously limit the legalistic category, I present the course of an argument: separation and divisional interrelation. First, it is beneficial to reintroduce the separate Hartian distinctions of role-responsibility and liability-responsibility. As we noted earlier in this paper, role-responsibility and liability-responsibility can be classified into different categories, the legal and non-legal. Then, we interpret shared responsibility as a duty of the role as a citizen. As such, this combined political role (Young-Hart) category of responsibility implies that all participants in social processes are supposed to have political responsibility to change the structure. Hereupon, political-role-responsibility is differentiated according to the different roles each individual has. Since most individuals are not legal officials who have $a$ role in pursuing liability, the separation of liability-responsibility and role-responsibility allows the idea that ordinary citizens have a role-responsibility to take political action against structural injustice, rather than to concentrate on blaming others. Further, we also need to clarify how two divisions interrelate. This depends on the understanding that the interaction between political decisions and legal decisions is regulated by a clear division of specification. Unlike international society, the domestic legal system allows this discussion (I will limit the discussion to a modern constitutional state that embodies the separation of powers). In general, the judiciary applies the law to restrict the political domain as far as an effective rule of law prevails. On the other hand, political activity produces laws and implements a scheme under the law to accommodate political requirements. In the specific context of the treatment for climate victims, this interrelation between the judiciary and politics primarily takes the form of the latter since countries have not yet implemented a legal institution to provide climate victims with a reparatory scheme ${ }^{10}$. Despite this fact, this paper has previously explicated the theoretical grounds of reparation for climate damage. Based on the above, it follows that all actors who participate in the process of structural injustice have first order role-responsibility, and a part of that political responsibility includes creating a legal scheme to attribute the relevant party liability-responsibility.

Let me recap how this combined view can avoid a back-looking view, blame-switching, and less concentration on the structure. The view is future-oriented to focus on structures since the role-responsibility as a citizen encourages one to change existing structures for the future. It also does not provoke blame-switching since shared responsibility is a first order responsibility that cannot be displaced to others as far as one is a participant in the structures. In other words, based on the liability model, individuals who commit specific injustices should be named and obliged to offer reparations by the official body (which is exemplified in the practice of litigations). Based on the shared responsibility model, the political responsibility of individuals demands the government or other bodies 
create such a reparative system that corrects injustices (which is exemplified in a variety of civil actions and political participations). This hybrid model of responsibility bridges political responsibility and legal responsibility, and envisions creating a political scheme of reparations for climate change victims.

\section{Conclusions}

In sum, this paper first examined how the distributive view of climate justice fails to discuss the damage caused by climate change, arguing that the scheme misses the need of reparation for climate loss and damage since it does not necessarily presuppose the unjust nature of the damage. Second, it showed that the concept of reparation, which is distinguished from compensation, holds more promise in giving the proper due for climate losses and damages. After comparing the liability model and the shared responsibility model proposed by Iris Young, the paper concluded by maintaining that the hybrid model of liability and shared responsibility can avoid the disadvantages of a liability claim.

The discussions of liability for climate damage have been a largely untouchable area in climate political theory even after the advancements in climate attribution science. It is partly because of its uncomfortable implications for international cooperation, and partly because of the considerations of political feasibility. Young's argument also finds negative aspects of liability, such as a back-looking view, blame-switching, and distraction from structures. However, the liability framework has an important role to play in the situation where structural climate injustice persists, where the link between the liable party and the harm is apparent, and where victims are expected to receive an unfavourable social reaction. Taking the perspective of climate victims reminds us of the need for reparation and compensation for their loss since the consideration of corrective justice legitimates a reparative scheme, and then supplementally supports the scheme of disaster victim assistance without questioning whether the victim deserves it or not.

While this paper classifies role- and liability-responsibilities and identifies the former as political responsibility, it does not differentiate the contents of the political-roleresponsibilities. The way how different actors who have different roles in a society discharge their responsibilities and the appropriate balance of their burden-how should democratic citizens contribute to creating a reparative system and how much should public officials or experts undertake the task?-should be elaborated in future research.

Funding: This work was supported by the project to support research on social aspects of geological disposal II in the fiscal year 2020-2021 conducted by The Nuclear Waste Management Organization of Japan.

Acknowledgments: I deeply appreciate Makoto Usami for his advice and precious comments on an early draft. I also thank Yan Hui Goh for her careful proofreading and comments, which greatly contributed to improvements of the manuscript. I also appreciate the support for my research from Takayuki Kira, PI of the above research project. He gave beneficial advice on the manuscript. My gratitude also goes to three anonymous reviewers who read in a detailed way and gave helpful comments.

Conflicts of Interest: The author declares no conflict of interest.

\section{Notes}

1 The first event attribution study was published in 2004, and analysed the link between anthropogenic climate change and the 2003 European heatwave, which resulted in widespread heat-related deaths across Western Europe [2]. Recently, Explaining Extreme Events of 2019 from a Climate Perspective, published in January 2021, also found substantial anthropogenic contribution to extreme events such as heatwaves, droughts, typhoons, and fires [3].

2 Exceptional literature written by political philosophers, see [4-6]. Justice for climate refugees has been discussed since a relatively early stage, see for example, ref. [7-9]. There are an increasing number of papers on climate loss and damage from the policy analysis perspective. For the current discussion, see for example, papers in [10,11]. From the perspective of mitigation and adaptation policies, the discussion of loss and damage is classified as a non-ideal situation. Political theorists step into the question of a non-ideal world, but they do not primarily focus on the just treatment for failure of adaptation (see for example, ref. [12,13]). 
3 See generally, ref. [18] (pp. 18-20). These litigants typically seek damages associated to Carbon Major's emissions. Other types of lawsuits focus on the sale of the fossil fuels [19], misleading the public about climate science ('greenwashing'), or inadequate disclosure of climate risk [20].

4 In addition to the intergenerational and global dimension, theorists provide other dimensions for characterizing climate justice: For example, Simon Caney adds the environmental sensitive distributive justice which Rawlsian's distributive scheme does not accommodate [25] (pp. 123-124); Stephan Gardiner formulates the theoretical dimension which strengthens the moral corruption related to climate change [23].

5 Political philosophers have been disputing the conception of distributive justice and criticize that it lacks recognition as a key element of justice. Nancy Fraser proposed a trivalent understanding of justice consisting of distributive, recognition, and participatory elements [38], while Iris Young focuses on oppression caused by misrecognition [39]. Some critics focus not only on a distributive principle but on how we translate distribution into functioning lives [40]. David Shrosberg combines these 'non-mainstream' justice theories with environmental justice and especially advances the recognitional and participatory notion of justice [41] (ch. 6).

6 According to the definition of IPCC, climate vulnerability refers to ' $\mathrm{t}$ ] he propensity or predisposition to be adversely affected' which encompasses 'a variety of concepts and elements including sensitivity or susceptibility to harm and lack of capacity to cope and adapt' [42] (p. 5). Additionally, I use the term 'refugee' based on the current legal situation; while the U.N. Refugee Convention 1951 excludes migrants displaced solely by changes to their environment, the UN Human Rights Committee delivered the decision on 2020 to endorse the interpretation that the rights and duties on the convention are applicable to those who have to displace due to the threat of climate change (Ioane Teitiota v. New Zealand, CCPR/C/127/D/2728/2016, UN Human Rights Committee, 7 January 2020, available at: https:/ / www.refworld.org/cases,HRC,5e26f7134.html accessed on 1 May 2021).

7 There are number of litigants based on the recent scientific research and explicitly cite the share of total carbon dioxide emissions attributable to individual defendants, as well as how much they have contributed to measured climate change-related impacts. For example, an environmental group commenced proceedings against Shell, alleging that Shell is responsible for $1.8 \%$ of the total increase in carbon dioxide in the atmosphere, $1.6 \%$ of the measured rise in global temperatures, and $1.4 \%$ of measured sea-level rise (Milieudefensie et al. v. Royal Dutch Shell plc, 2019).

8 The discussion on environmental harm in this paper is limited in that it presupposes an anthropocentric position. On the other hand, the harm against non-human beings can be discussed in the field of ecological justice, which cannot be investigated in this paper.

9 An example is a discrimination against disaster victims who are voluntarily or involuntarily evacuated from the disaster-stricken homeland. Typically, the case of evacuation from the contaminated nuclear area of Fukushima shows that discrimination against victims. It obliged some of them to make lawsuits in order to identify the liability of the government and the nuclear power plant company, declining readier alternative dispute resolution. In general, alongside economic interests, clarifying facts or an open resolution in a public forum are the popular reasons for pursuing liability [63] (p. 53-54).

10 Even though vulnerable Pacific countries, including Kiribati, created migration programs for their nation, it is nonsense to call it 'reparation' since those governments have not contributed to the significant emissions of GHG and therefore are far beyond being liable to their nation.

\section{References}

1. Caney, S. Climate Justice. In Stanford Encyclopedia of Philosophy; Zalta, E.N., Ed.; Metaphysics Research Lab: Stanford, CA, USA, 2020.

2. Stott, P.A.; Stone, D.A.; Allen, M.R. Human Contribution to the European Heatwave of 2003. Nat. Cell Biol. 2004, 432, 610-614. [CrossRef]

3. Herring, S.C.; Christidis, N.; Hoell, A.; Hoerling, M.P.; Stott, P.A. Explaining Extreme Events of 2019 from a Climate Perspective. Bull. Am. Meteorol. Soc. 2021, 102, S1-S116. [CrossRef]

4. Page, E.A.; Heyward, C. Compensating for Climate Change Loss and Damage. Polit. Stud. 2016, 65, 356-372. [CrossRef]

5. Wallimann-Helmer, I. Justice for Climate Loss and Damage. Clim. Chang. 2015, 133, 469-480. [CrossRef]

6. Wallimann-Helmer, I.; Meyer, L.; Mintz-Woo, K.; Schinko, T.; Serdeczny, O. The Ethical Challenges in the Context of Climate Loss and Damage. In Loss and Damage from Climate Change. Concepts, Methods and Policy Options; Mechler, R., Bouwer, L.M., Schinko, T., Surminski, S., Linnerooth-Bayer, J., Eds.; Springer: Cham, Switzerland, 2019.

7. Buxton, R. Reparative Justice for Climate Refugees. Philosophy 2019, 94, 193-219. [CrossRef]

8. Posner, E.A.; Vermeule, A. Reparations for Slavery and Other Historical Injustices. Colum. Law Rev. 2003, 103, 689-748. [CrossRef]

9. Heyward, C. Climate Change as Cultural Injustice. In New Waves in Philosophy; Brooks, T., Ed.; Palgrave Macmillan: London, UK, 2014.

10. Mechler, R.; Bouwer, L.M.; Schinko, T.; Surminski, S.; Linnerooth-Bayer, J. (Eds.) Loss and Damage from Climate Change. Concepts, Methods and Policy Options; Springer: Cham, Switzerland, 2019.

11. James, R.A.; Jones, R.G.; Boyd, E.; Young, H.R.; Otto, F.E.L.; Huggel, C.; Fuglestvedt, J.S. Attribution: How Is It Relevant for Loss and Damage Policy and Practice. In Loss and Damage from Climate Change; Springer International Publishing: Cham, Switzerland, 2019; pp. 113-154. 
12. Gardiner, S.M. A Perfect Moral Storm: The Ethical Tragedy of Climate Change; Oxford University Press: Oxford, UK, 2011.

13. Heyward, C.; Roser, D. (Eds.) Climate Justice in a Non-Ideal World; Oxford University Press: Oxford, UK, 2016.

14. UNFCCC. Decision 2/CP.20, Warsaw International Mechanism for Loss and Damage Associated with Climate Change Impacts, UN Doc FCCC/CP/2014/10/Add.2; UNFCCC: Bonn, Germany, 2014.

15. UNFCCC. Decision 1/CP.21, Adoption of the Paris Agreement, UN Doc FCCC/CP/2015/10/Add.1; UNFCCC: Bonn, Germany, 2015.

16. Dryzek, J.S.; Norgaard, R.B.; Schlosberg, D. (Eds.) Climate Change and Society: Approaches and Responses. In The Oxford Handbook of Climate change and Society; Oxford University Press: Oxford, UK, 2012; pp. 1-17.

17. Pickering, J.; Barry, C. On the Concept of Climate Debt: Its Moral and Political Value. Crit. Rev. Int. Soc. Polit. Philos. 2012, 15, 667-685. [CrossRef]

18. Setzer, J.; Byrnes, R. Global Trends in Climate Change Litigation: 2020 Snapshot; Grantham Research Institute on Climate Change and the Environment and Centre for Climate Change Economics and Policy: London, UK, 2020.

19. Varvastian, S.; Kalunga, F. Transnational Corporate Liability for Environmental Damage and Climate Change: Reassessing Access to Justice after Vedanta v. Lungowe. Transnatl. Environ. Law 2020, 9, 323-345. [CrossRef]

20. Marjanac, S.; Patton, L. Extreme Weather Event Attribution Science and Climate Change Litigation: An Essential Step in the Causal Chain? J. Energy Nat. Resour. Law 2018, 36, 265-298. [CrossRef]

21. Weisbach, D.A. The Role of Claims of Justice in Climate Change Policy. In Debating Climate Ethics; Gardiner, S.M., Weisbach, D.A., Eds.; Oxford University Press: Oxford, UK, 2016; pp. 201-240.

22. Posner, E.A.; Weisbach, D. Climate Change Justice; Princeton University Press: Princeton, NJ, USA, 2010.

23. Jamieson, D. Ethics, Public Policy, and Global Warming. In Climate Ethics; Gardiner, M.S., Caney, S., Jamieson, D., Shue., H., Eds.; Oxford University Press: Oxford, UK, 2010.

24. Page, E. Climate Change, Justice and Future Generations; Edward Elgar Publishing: Cheltenham, UK, 2007.

25. Caney, S. Cosmopolitan Justice, Responsibility, and Global Climate Change. In Climate Ethics; Gardiner, S.M., Caney, S., Jamieson, D., Shue, H., Eds.; Oxford University Press: Oxford, UK, 2010.

26. Vanderheiden, S. Atmospheric Justice: A Political Theory of Climate Change; Oxford University Press: Oxford, UK, 2008.

27. Gardiner, S.M. Climate Justice. In The Oxford Handbook of Climate Change and Society; Dryzek, J.S., Norgaard, R.B., Schlosberg, D., Eds.; Oxford University Press: Oxford, UK, 2012.

28. Shue, H. Climate Justice: Vulnerability and Protection; Oxford University Press: Oxford, UK, 2014.

29. Neumayer, E. In Defence of Historical Accountability for Greenhouse Gas Emissions. Ecol. Econ. 2000, 33, 185-192. [CrossRef]

30. Garvey, J. The Ethics of Climate Change: Right and Wrong in a Warming World; Continuum International Publishing Group: London, UK, 2008.

31. Caney, S. Justice and the Distribution of Greenhouse Gas Emissions. J. Glob. Ethics 2009, 5, 125-146. [CrossRef]

32. Singer, P. One World: The Ethics of Globalization; Yale University Press: New Haven, CT, USA, 2002.

33. Williston, B. The Ethics of Climate Change: An Introduction; Routledge: New York, NY, USA, 2018.

34. Miller, D. Global Justice and Climate Change: How Should Responsibilities Be Distributed? Tann. Lect. Hum. Values 2008, 28, 117-156.

35. Holland, B. Allocating the Earth: A Distributional Framework for Protecting Capabilities in Environmental Law and Policy; Oxford University Press: Oxford, UK, 2014; Volume 14.

36. Jamieson, D. Adaptation, Mitigation, and Justice. In Climate Ethics; Gardiner, S.M., Caney, S., Jamieson, D., Shue, H., Eds.; Oxford University Press: Oxford, UK, 2010.

37. Vanderheiden, S. Globalizing Responsibility for Climate Change. Ethics Int. Aff. 2011, 25, 65-84. [CrossRef]

38. Fraser, N.; Honneth, A. Redistribution or Recognition? A Political-Philosophical Exchange; Verso: Brooklyn, NY, USA, 2003.

39. Young, I.M. Justice and the Politics of Difference; Princeton University Press: Princeton, NJ, USA, 1990.

40. Nussbaum, M.; Sen, A. (Eds.) The Quality of Life; Oxford University Press: Oxford, UK, 1993.

41. Schlosberg, D. Defining Environmental Justice; Oxford University Press: Oxford, UK, 2007.

42. Allen, S.K.; De Barros, V.P.; Burton, I.; Campbell-Lendrum, D.; Cardona, O.-D.; Cutter, S.L.; Dube, O.P.; Ebi, K.L.; Field, C.B.; Handmer, J.W.; et al. Summary for Policymakers. In Managing the Risks of Extreme Events and Disasters to Advance Climate Change Adaptation. Special Report of the Intergovernmental Panel on Climate Change; Field, C.B., Barros, V., Stocker, T.F., Dahe, Q., Eds.; Cambridge University Press: Cambridge, CA, USA, 2012; pp. 3-22. [CrossRef]

43. Posner, R.A. The Concept of Corrective Justice in Recent Theories of Tort Law. J. Leg. Stud. 1981, 10, 187-206. [CrossRef]

44. Weinrib, E.J. Corrective Justice in a Nutshell. Univ. Tor. Law J. 2002, 52, 349-356. [CrossRef]

45. Fletcher, G.P. Fairness and Utility in Tort Theory. Harv. Law Rev. 1972, 85, 537-573. [CrossRef]

46. Caney, S. Climate change, human rights and moral thresholds. In Human Rights and Climate Change; Humphreys, S., Ed.; Cambridge University Press: Cambridge, UK, 2009; pp. 69-90. [CrossRef]

47. The High Representative, European Commission to the European Council. Climate Change and International Security; European Commission: Brussels, Belgium, 2008.

48. U. N. D. Programme. Human Development Report 2007/2008; Palgrave Macmillan: London, UK, 2007.

49. Goodin, R.E. Theories of Compensation. Oxf. J. Leg. Stud. 1989, 9, 56-75. [CrossRef]

50. Boxill, B.R. The Morality of Reparation. Soc. Theory Pr. 1972, 2, 113-123. [CrossRef]

51. Thompson, J. Taking Responsibility for the Past: Reparation and Historical Injustice; Polity: Cambridge, UK, 2002. 
52. Burkett, M. Climate Reparations. Melb. J. Int. Law 2009, 10, 509-542.

53. UNFCCC. A Literature Review on the Topics in the Context of Thematic Area 2 of the Work Programme on Loss and Damage: A Range of Approaches to Address Loss and Damage Associated with the Adverse Effects of Climate Change; UNFCCC: New York, NY, USA, 2012.

54. de Shalit, A. Climate Change Refugees, Compensation, and Rectification. Monist 2011, 94, 310-328.

55. Spinner-Halev, J.; Theiss-Morse, E. National Identity and Self-Esteem. Perspect. Polit. 2003, 1, 515-532. [CrossRef]

56. Brophy, A.L. Reparations: Pro and Con; Oxford University Press: Oxford, UK, 2006.

57. de Greiff, P. (Ed.) Justice and Reparations. In The Handbook of Reparations; Oxford University Press: Oxford, UK, 2006 ; pp. 451-472.

58. Hart, H.L.A. Punishment and Responsibility: Essays in the Philosophy of Law, 2nd ed.; Oxford University Press: Oxford, UK, 2008.

59. Young, I.M. Responsibility for Justice; Oxford University Press: Oxford, UK, 2011.

60. Eckersley, R. Responsibility for Climate Change as a Structural Injustice. In The Oxford Handbook of Environmental Political Theory; Gabrielson, T., Hall, C., Meyer, J.M., Schlosberg, D., Eds.; Oxford University Press: Oxford, UK, 2016.

61. Langlois, A. Social Connection \& Political Responsibility: An Engagement with Iris Marion Young. St Antony's Int. Rev. 2014, 10, 43-63.

62. Shklar, N. Legalism; Harvard University Press: Cambridge, MA, USA, 1964.

63. Society for the Study of the Civil Procedural System (Ed.) Report on Japan's 2011 Civil Litigation Survey; Jigakusha Publishing: Tokyo, Japan, 2014. 